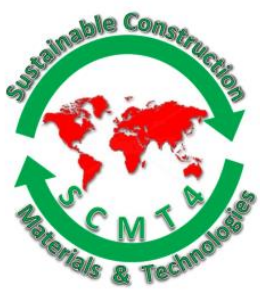

SCMT4

Las Vegas, USA, August 7-11, 2016

\title{
Performance of Polypropylene Fiber Reinforced Self-Compacting Lightweight Concrete in Hardened State
}

\author{
Faiz A. Mirza ${ }^{1 a}$, and Ayman G. Abdel-Rhaman ${ }^{1 b}$ \\ ${ }^{1}$ P.O. Box: 6298, , Civil Engineering Department, Umm Al-Qura University, Makkah, Saudi Arabia. \\ ${ }^{l a}$ Email: <faizmirza@hotmail.com>, ${ }^{1 b}$ Email: <agg5522@hotmail.com>.
}

\begin{abstract}
This study investigates how the inclusion of polypropylene fibers affects the mechanical properties of selfcompacting fiber lightweight concrete (SCFLWC) made from natural lightweight aggregate (scoria) that existed in the western province of Saudi Arabia. Mixes with different fiber volume fractions (0.0, 0.2, 0.4 and $0.6 \%)$ at different levels of fly ash $(0.0,10,20$ and 30\%) as a replacement by weight of cement were prepared and tested. The performance of SCFLWC were studied in terms of mechanical and transport properties. The mechanical properties were conducted by comprising the compressive, splitting tensile \& flexural strengths and the modulus of elasticity at 28 and 90 days. While transport properties were measured using the rapid chloride penetration test at 28 and 90 days. All mixes achieve self-compacting properties using polypropylene fiber up to $0.4 \%$ fiber content. The SCFLWC mixes have a slump flow in the range of 610-690 $\mathrm{mm}$. Polypropylene fiber have a little effect on the compressive strength and elastic modulus of SCFLWC, however applying these fibers at their maximum percentage volume fraction determined through this study, increased the tensile strength and the flexural strength especially at 90 days. However applying polypropylene fibers have a slight effect on the chloride ion penetration.
\end{abstract}

\section{INTRODUCTION}

Self-compacting concrete (SCC) consists of the same components as conventional concrete i.e. cement, water, aggregates, admixtures, and mineral additions, but the final composition of the mixture and its fresh characteristics are different. This difference is caused by containing larger quantities of mineral fillers such as Limestone Powder (LP) or fly ash as well as higher quantities of high-range water-reducing admixtures (HRWRA), and reducing the maximum size of the aggregate. Nowadays, it is well documented that the fibers added to concrete can substantially improve many of its engineering properties. FRSCC provides the benefits of the SCC technology with the advantages of the fiber addition to a brittle cementitious matrix. Brittle fracture of SFRSCC significantly decreases which will be ductile by bridging between sides of cracks under various loads [Khayat and Schutter 2014; Madandoust et al 2015].

Self-Compacting Concrete (SCC) mixtures are divided into three types; admixture type (it is produced using viscosity modifying agent, VMA), combination type (it is produced using fly ash and VMA), and powder type (it is produced using fly ash and super plasticizer) [D'Aloia et al 2006; Corinaldesi and Moriconi 2004]. The increasingly extensive developments in the construction industry throughout the world along 
with the need for the application of concretes with such qualities as of the SCC, has lead to many studies on such types of concretes. One of the most crucial factors in the design and construction of structures is the considerable amount of weight of dead-load mainly due to the ceiling and the separating walls. Thus, it is evident that using lightweight materials in the structure components considerably reduces the dead-load, which could result in a cost-effective construction plan. It is also evident that applying lightweight concretes in many such structures as bridges with long spans, results in the decrease of the area of the bridge section. Lightweight concrete is known with its advantage of reducing the self-weight of the structures, reducing the areas of sectional members as well as making the construction convenient [Shannag 2011; Cui 2012]. Thus, the construction cost can be saved when applied to structures such as long span bridge and high rise buildings [Wang et al 2003; Alengaram 2013].

The lightweight concrete requires specific mix design method that is quite different from conventional concrete. Using conventional mix design method would give raise the material segregation as well as lower the strength by the reduced weight of the aggregate. To avoid such problems, it is recommended to apply the mix design method of high performance self-compacting concrete for the lightweight concrete that have excellent in segregation resistance ability and its flowability at its fresh condition [Wu 2009]. Selfcompacting lightweight aggregate concrete (SCLC) is a kind of high performance concrete developed from self-compacting concrete (SCC). SCLC combines the favorable properties of lightweight aggregate concrete (LWAC) and SCC, needs no external vibration, and can spread into place, fill the formwork and encapsulate reinforcement without any bleeding or segregation. As another advantage, SCLC efficiently reduces the self-weight of the structure and the on-site noise level and can be used for maintenance and repairs of concrete structures. Workability is a crucial factor that affects the application and physicomechanical properties of SCLC, since SCLC of practical use is required to have high fluidity, deformability, good filling ability, and moderate resistance to segregation. To ensure that reinforcement can be encapsulated and that the formwork can be filled completely, a favorable workability is essential for fresh SCLC. In addition, aggregate particles in SCLC are required to have uniform distribution in the specimen and the minimum segregation risk should be maintained during the process of transportation and placement [Torrijos et al 2008; Bogas 2012].

The use of Fiber Reinforced Concretes (FRC) has increased in building structures because the reinforced fibers in concrete may improve the toughness, flexural strength, tensile strength, impact strength as well as the failure mode of the concrete. It has also been known that addition of fibers in concrete has little or no effect on the compressive strength and the modulus of elasticity [Abukhashaba et al 2014; Salehian and Barros 2015]. Use of fibers into SCC mixes has been presented by many researchers [El-Dieb and RedaTaha 2012; Akcay and Tasdemir 2012; Beyciog and Aruntas 2014]. Depending on many parameters such as maximum aggregate size, fiber volume, fiber type, fiber geometry, and fiber aspect ratio, fiber inclusion to concrete reduces the workability of concrete [Ferrara et al 2012; Hassanpour 2012].

This study investigates and quantifies how the inclusion of polypropylene of fibers affects the characteristics of self compacting fiber light weight concrete (SCFLWC) in hardened state. the Mechanical properties, namely the compressive, splitting tensile \& flexural strengths, elastic modulus of selfcompacting fiber lightweight concrete mixtures (its density is $1700-2000 \mathrm{~kg} / \mathrm{m}^{3}$ ) that contain polypropylene fibers were determined at 28 and 90 days age, while transport properties was rapid chloride penetration resistance.

\section{EXPERIMENTAL INVESTIGATION}

\section{Materials}

1. Ordinary Portland cement: OPC equivalent to ASTM Type I locally produced with specific surface area $3350 \mathrm{~cm}^{2} / \mathrm{g}$ and specific gravity $3.16 \mathrm{~g} / \mathrm{cm}^{3}$ was used. The level of cement content was kept constant 450 $\mathrm{kg} / \mathrm{m}^{3}$ for all mixtures. 
2. Fly ash: FA as fine powder form was used with surface area of $22,000 \mathrm{~cm}^{2} / \mathrm{gm}$ and at different levels namely: $0.0,10,20$ and $30 \%$ as a partial replacement by weight of cement content. The chemical composition of cement and fly ash are reported in Table 1.

Table 1. Chemical composition of cement and fly ash

\begin{tabular}{|c|c|c|}
\hline Chemical Composition & Cement (\%) & Fly ash (\%) \\
\hline Silicon dioxide $\left(\mathrm{SiO}_{2}\right)$ & 21.6 & 54.9 \\
\hline Aluminum oxide $\left(\mathrm{Al}_{2} \mathrm{O}_{3}\right)$ & 4.13 & 25.8 \\
\hline Ferric oxide $\left(\mathrm{Fe}_{2} \mathrm{O}_{3}\right)$ & 4.57 & 6.90 \\
\hline Calcium oxide $(\mathrm{CaO})$ & 64.4 & 8.70 \\
\hline Magnesium oxide $(\mathrm{MgO})$ & 1.06 & 1.80 \\
\hline Sodium oxide $\left(\mathrm{Na}_{2} \mathrm{O}\right)$ & & 0.30 \\
\hline Potassium oxide $\left(\mathrm{K}_{2} \mathrm{O}\right)$ & 0.11 & 0.10 \\
\hline Sulfur trioxide $\left(\mathrm{SO}_{3}\right)$ & 0.56 & 0.60 \\
\hline
\end{tabular}

3. Fine aggregate: sand of 2.62 specific gravity and 2.87 fineness modulus was used. The sieve analysis of sand is reported in Table 2. The fine aggregate was confirmed with the ASTM requirements (ASTM C$33)$.

Table 2. Sieve analysis of fine aggregates

\begin{tabular}{|c|c|c|}
\hline Sieve No. & $\begin{array}{c}\text { Percent passing } \\
(\%)\end{array}$ & $\begin{array}{c}\text { ASTM limit } \\
(\%)\end{array}$ \\
\hline No.4 & 100 & $95-100$ \\
\hline No.8 & 100 & $80-100$ \\
\hline No.16 & 93.94 & $50-85$ \\
\hline No.30 & 68.69 & $25-60$ \\
\hline No.50 & 15.15 & $10-30$ \\
\hline No.100 & 1.52 & $2-10$ \\
\hline Pan & 0 & $-\cdots---$ \\
\hline
\end{tabular}

4. Pozzolanic natural lightweight aggregate (scoria): LWA that existed in the western province of Saudi Arabia was used. It was volcanic in origin and is geologically categorized as pozzolanic scoria and tuff. This type of lightweight aggregate (LWA) was available in different sizes, which used as coarse aggregate, with different size of 5-14 mm. The LWA was also extensively tested at the quality control laboratories of Saudi Arabian Standards Organization (SASO). The results show that values for coarse aggregate were within the limit specified by ASTM C-332. This happened for both grading and unit weight. Tests conducted by SASO on light weight concrete panels made from LWA, were yielded a thermal conductivity value equal to $0.140 \mathrm{w} / \mathrm{m}-\mathrm{k}$ which less than 0.43 as required by ASTM C-332. The Scoria aggregates were used in Saturated Surface Dry (SSD) condition. The physical properties of LWA, which are used in this research, are given in Table 3. 
Table 3. Physical properties of LWA

\begin{tabular}{|l|c|}
\hline Color & Grayish/Black \\
\hline Bulk density $\left(\mathrm{kg} / \mathrm{m}^{3}\right)$ for coarse aggregate & $615-800$ \\
\hline Bulk density $\left(\mathrm{kg} / \mathrm{m}^{3}\right)$ for fine aggregate & $850-1075$ \\
\hline Bulk specific gravity ( SSD ) & 1.85 \\
\hline Oven dry specific gravity & 1.66 \\
\hline L-A abrasion value & $28-33$ \\
\hline Thermal conductivity of insolating concrete from "cicolite" & $0.140 \mathrm{~W} / \mathrm{mk}$ \\
\hline Fire rating & $3 \mathrm{hours}$ \\
\hline Noise attenuation & $3-6 \mathrm{~dB}$ \\
\hline
\end{tabular}

5. Polypropylene fibers: PPF was used in this study at different fiber volume fractions namely: 0.2, 0.4 and 0.6. The properties of fiber are given in Table 4.

Table 4. The properties of polypropylene fibers

\begin{tabular}{|c|c|c|c|c|c|}
\hline $\begin{array}{c}\text { Density } \\
\left(\mathrm{Kg} / \mathrm{m}^{3}\right)\end{array}$ & $\begin{array}{c}\text { Tensile strength } \\
(\mathrm{MPa})\end{array}$ & $\begin{array}{c}\text { Elongation at peak } \\
(\%)\end{array}$ & $\begin{array}{c}\text { Young's modulus } \\
(\mathrm{GPa})\end{array}$ & $\begin{array}{c}\text { Diameter } \\
(\mathrm{mm})\end{array}$ & $\begin{array}{c}\text { Length } \\
(\mathrm{mm})\end{array}$ \\
\hline 910 & 450 & 15 & 4.5 & 0.015 & 15 \\
\hline
\end{tabular}

6. Chemical admixture: A type-F naphthalene sulphonate formaldehyde condensate superplasticizer (SP) was conformed the ASTM C-494 requirements were incorporated in all mixes. The dosage of the admixture is $1.2 \% \pm$ justify amount.

7. Viscosity enhancement agent: VEA was used at level $0.4 \%$ by weight of cement content in all mixes. 8. Water: Clean tap water, with water-binder ratio (w/b) equal to 0.45 was kept fixed in all mixes in this study.

Mix design. A rational mix-design method for self-compacting concrete using a variety of materials is necessary. The coarse and fine aggregate contents were fixed so that self compact ability could be achieved easily by adjusting the water binder ratio and super plasticizer dosage. For the experiments, 16 series of self-compacting concrete mix represent the main variables were mixed: Three different levels of polypropylene fiber volume fractions $0.2,0.4$ and 0.6 and three levels of fly ash, $10 \%, 20 \%$ and $30 \%$ as a partial replacement of cement by weight of cement were used in this work, in addition to control mix with no fiber and $0 \%$ fly ash. Also the dosage of viscosity enhancement agent (VEA) of $0.4 \%$ was used at cement content $450 \mathrm{~kg} / \mathrm{m}^{3}$. The water binder ratio (W/B) was kept constant and equal to 0.45 , for all mixture. The mixtures proportions were reported in Table 5. 
Table 5. Mix proportions of SCFLWC containing polypropylene fibers in $\left(\mathrm{kg} / \mathrm{m}^{3}\right)$

\begin{tabular}{|c|c|c|c|c|c|c|c|}
\hline Mix. No. & Cement & Fly ash & Sand & Scoria & Water & P.P fibers & S.P \\
\hline 1 & 450 & 0 & 430 & 610 & 202.5 & 0 & 17 \\
\hline 2 & 405 & 45 & 430 & 610 & 202.5 & 0 & 17 \\
\hline 3 & 360 & 90 & 430 & 610 & 202.5 & 0 & 18 \\
\hline 4 & 315 & 135 & 430 & 610 & 202.5 & 0 & 18.8 \\
\hline 5 & 450 & 0 & 430 & 610 & 202.5 & $1.8(0.2 \%)$ & 17 \\
\hline 6 & 450 & 0 & 430 & 610 & 202.5 & $3.6(0.4 \%)$ & 18 \\
\hline 7 & 450 & 0 & 430 & 610 & 202.5 & $4.8(0.6 \%)$ & 18.8 \\
\hline 8 & 405 & 45 & 430 & 610 & 202.5 & 1.8 & 17.4 \\
\hline 9 & 405 & 45 & 430 & 610 & 202.5 & 3.6 & 18.8 \\
\hline 10 & 405 & 45 & 430 & 610 & 202.5 & 4.8 & 19.3 \\
\hline 11 & 360 & 90 & 430 & 610 & 202.5 & 1.8 & 17.4 \\
\hline 12 & 360 & 90 & 430 & 610 & 202.5 & 3.6 & 18.8 \\
\hline 13 & 360 & 90 & 430 & 610 & 202.5 & 4.8 & 19.3 \\
\hline 14 & 315 & 135 & 430 & 610 & 202.5 & 1.8 & 17.4 \\
\hline 15 & 315 & 135 & 430 & 610 & 202.5 & 3.6 & 18.8 \\
\hline 16 & 315 & 135 & 430 & 610 & 202.5 & 4.8 & 19.3 \\
\hline
\end{tabular}

\section{SPECIMENS PREPARATION AND TESTING PROCEDURES}

Mixing procedures. In the production of SCFLWC the mixing sequence and duration are very important. Thus, the procedure for batching and mixing was employed to secure the same homogeneity and uniformity in all mixtures. The batching sequence consisted of homogenizing the fine and coarse aggregates for one minute in a rotary planetary mixer, then adding about one half of the mixing water to the mixer and continue mixing for one minute. Thereafter, the aggregates were left to absorb the water in the mixer for about 1 min. After that cement and fly ash were added, and then mixing was resumed for another minute. Then, the SP and VEA with remaining water was introduced to the concrete mixture and mixed for $3 \mathrm{~min}$. The polypropylene fiber was added in the mixer at the final process. Eventually, the concrete mixture was mixed for an additional 2 min to complete the mixing sequence. For this, trial batches were produced for each mixture till the desired slump flow was obtained by adjusting the dosage of the superplasticizer. The casting immediately followed mixing, after carrying out the tests for fresh properties. The top surface of the specimens was scraped to remove excess material and achieve smooth finish. The specimens were removed from molds after $24 \mathrm{~h}$ and then cured in water till testing date.

Hardened properties. Specimens were tested following relevant ASTM standards after 28, and 90 days for evaluation of compressive [ASTM C39], splitting tensile [ASTM C496], and flexural strengths [ASTM C78] as well as modulus of elasticity [ASTM C469].

1. Compressive, tensile and flexural strengths. All specimens of SCFLWC have been manufactured without compaction. The molds were removed after $24 \mathrm{~h}$ followed by curing operation in water at approximately $200 \mathrm{C}$ until testing date which was carried out at the age of 28 days.

Compressive strength of SCFLWC was measured according to ASTM C39 by means of a $2000 \mathrm{KN}$ capacity testing machine. Compressive strength of the concrete was tested at 28 days; the compressive strength was obtained for a cylinder of $150 \times 300 \mathrm{~mm}$ in dimension. 
The splitting tensile strength was determined at day 28 age on cylinders measuring $150-\mathrm{mm}$ diameter and $300 \mathrm{~mm}$ height and cured in water until the date of test according the ASTM C496.

The flexural strength was determined according to ASTM C78. End capped 100 x 100x $500 \mathrm{~mm}$ prism specimens were cured in water and tested at ages of 28 days for different mixtures. Three specimens of each mixture were tested and the mean value was reported.

2. Modulus of Elasticity. The procedure for measuring the static modulus of elasticity in compression is described in ASTM C469. Concrete cylinders were the same size as those used for compressive strength measurements i.e. $150 X 300 \mathrm{~mm}$ were used. The applied load and longitudinal strain were recorded when the longitudinal strain is 50 millionths and when the applied load is equal to $40 \%$ of the cylinder compressive strength. The compressive strength was determined on companion specimens prior to testing for modulus of elasticity. The modulus of elasticity is calculated as the slope of the straight line between the $40 \%$ compressive stress point and the 50 millionths strain point. The modulus of elasticity was determined at 28 days.

3. Transport properties (Rapid chloride permeability test). The chloride permeability test was conducted to assess the concrete quality as per ASTM C1202. To measure the permeability cylindrical specimens of size $100 \mathrm{~mm}$ diameter and $50 \mathrm{~mm}$ height were cut in cylinders. Only the central part of the cylinders was kept for the measures. A potential difference of $60 \mathrm{~V} \mathrm{DC}$ was maintained across the specimen. One of the surfaces was in contact with a sodium chloride solution $(\mathrm{NaCl})$ and the other with a sodium hydroxide solution $(\mathrm{NaOH})$. The total charge passing through in $6 \mathrm{~h}$ was measured, indicating the degree of resistance of the specimen to chloride ion penetration.

\section{RESULTS AND DISCUSSIONS}

Properties of fresh concrete. The test results of various fresh properties were disused in details in first part of this study. Tests include: slump flow test (slump flow diameter and $\mathrm{T}_{50 \mathrm{~cm}}$ ), J-ring test (flow diameter and difference in concrete height inside and outside $\mathrm{J}$-ring $\left(\mathrm{h}_{2}-\mathrm{h}_{1}\right)$ ), L-box test (time taken to reach $400 \mathrm{~mm}$ distance $\mathrm{T}_{400 \mathrm{~mm}}$; time taken to reach $600 \mathrm{~mm}$ distance $\mathrm{T}_{600 \mathrm{~mm}}$, and time taken to reach $800 \mathrm{~mm}$ distance $\mathrm{T}_{\mathrm{L}}$, ratio of heights at the two edges of L-box $\left(\mathrm{H}_{2} / \mathrm{H}_{1}\right)$ ), V-funnel test (time taken by concrete to flow through $\mathrm{V}$-funnel after $10 \mathrm{~s} \mathrm{~T}_{10 \mathrm{~s}}$, time taken by concrete to flow through $\mathrm{V}$-funnel after $5 \mathrm{~min} \mathrm{~T}_{5 \mathrm{~min}}$ ), and finally $\mathrm{U}$ box test (difference in height of concrete in two chambers $\left(\mathrm{H}_{2}-\mathrm{H}_{1}\right)$ ) for various mix compositions. The slump flow represents the mean diameter of the mass of concrete after release of a standard slump cone; the diameter is measured in two perpendicular directions. According to EFNARC [JSCE 1998], a slump flow ranging from 500 to $700 \mathrm{~mm}$ is considered as the slump required for a concrete to be self-compacted. At more than $700 \mathrm{~mm}$ the concrete might segregate, and at less than $500 \mathrm{~mm}$ the concrete is considered to have insufficient flow to pass through highly congested reinforcement. The stability of SCC mixes was evaluated through the V-shaped funnel test. A V-funnel test flow time less than $12 \mathrm{~s}$ is recommended for a concrete to qualify for an SCC. The range values were borrowed from testing methods for the self-compact concrete published by JSCE, [Libre 2011].

It is possible to produce and design SCFLWC mixes incorporating fly ash content up to $30 \%$ and polypropylene fiber at $0.4 \%$ volume fraction. The produced SCLWC mixes have a slump flow in the range of 610-690 mm, a flow time less than $5 \mathrm{~s}$, V-funnel time in the range of 5.5-11 s, L-box ratio was greater than 0.82 for all mixes and difference in height of concrete in two compartments in U-box in the range of $7-18 \mathrm{~mm}$. The presence of polypropylene fibers in SCFLWC greatly decreases the slump flow, where $0.4 \%$ of these fibers in the concrete reduce the flowability from $690 \mathrm{~mm}$ to $535 \mathrm{~mm}$ at $20 \%$ of fly ash content. The reduced slump flow for $0.2 \%$ and $0.4 \%$ of fiber usage is $584 \mathrm{~mm}$, and $535 \mathrm{~mm}$, respectively. Increasing the volume percentage of polypropylene fibers in SCFLWC reduces the filling height in U-box test, while the time of the V-funnel test is increased. 


\section{Test results for hardened concrete}

The results of mechanical and transport properties of SCFLWC are given in Table $6 \& 7$ for 28 and 90 days respectively.

Table 6. Mechanical and transport properties of SCFLWC mixes (28days)

\begin{tabular}{|l|c|c|c|c|c|}
\hline Mix No. & $\begin{array}{c}\text { Compressive } \\
\text { Strength } \\
(\mathrm{MPa})\end{array}$ & $\begin{array}{c}\text { Tensile } \\
\text { Strength } \\
(\mathrm{MPa})\end{array}$ & $\begin{array}{c}\text { Flexural } \\
\text { Strength } \\
(\mathrm{MPa})\end{array}$ & $\begin{array}{c}\text { Modulus of } \\
\text { Elasticity } \\
(\mathrm{GPa})\end{array}$ & $\begin{array}{c}\text { Charge } \\
\text { passed } \\
(\text { Coulombs })\end{array}$ \\
\hline $1(0 \% \mathrm{pp}, 0 \% \mathrm{FA})$ & 37 & 2.9 & 3.1 & 23.3 & 2200 \\
\hline $2(0 \% \mathrm{pp}, 10 \% \mathrm{FA})$ & 35.5 & 2.75 & 2.97 & 21.7 & 390 \\
\hline $3(0 \% \mathrm{pp}, 20 \% \mathrm{FA})$ & 33.5 & 2.65 & 2.75 & 19.9 & 650 \\
\hline 4(0\%pp,30\%FA) & 28.2 & 1.95 & 2.32 & 18.8 & 505 \\
\hline $5(0.2 \% \mathrm{pp}, 0 \% \mathrm{FA})$ & 35.5 & 2.93 & 3.3 & 24 & 1710 \\
\hline $6(0.4 \% \mathrm{pp}, 0 \% \mathrm{FA})$ & 33.8 & 2.97 & 3.34 & 23.2 & 1340 \\
\hline $7(0.6 \% \mathrm{pp}, 0 \% \mathrm{FA})$ & 27.5 & 2.87 & 3.26 & 23 & 1460 \\
\hline $8(0.2 \% \mathrm{pp}, 10 \% \mathrm{FA})$ & 33.3 & 3.00 & 3.51 & 22 & 890 \\
\hline $9(0.4 \% \mathrm{pp}, 10 \% \mathrm{FA})$ & 32.8 & 3.13 & 3.52 & 21.3 & 780 \\
\hline $10(0.6 \% \mathrm{pp}, 10 \% \mathrm{FA})$ & 27.8 & 2.91 & 3.24 & 21 & 930 \\
\hline $11(0.2 \% \mathrm{pp}, 20 \% \mathrm{FA})$ & 33.3 & 2.95 & 3.24 & 19.7 & 610 \\
\hline $12(0.4 \% \mathrm{pp}, 20 \% \mathrm{FA})$ & 32.3 & $3 . .01$ & 3.31 & 19.3 & 430 \\
\hline $13(0.6 \% \mathrm{pp}, 20 \% \mathrm{FA})$ & 27.2 & 2.90 & 3.11 & 19.5 & 700 \\
\hline $14(0.2 \% \mathrm{pp}, 30 \% \mathrm{FA})$ & 33 & 2.88 & 2.51 & 19 & 490 \\
\hline $15(0.4 \% \mathrm{pp}, 30 \% \mathrm{FA})$ & 32.1 & 2.94 & 2.66 & 18.8 & 410 \\
\hline $16(0.6 \% \mathrm{pp}, 30 \% \mathrm{FA})$ & 26.8 & 2.68 & 2.61 & 18.6 & 630 \\
\hline
\end{tabular}

Table 7. Mechanical and transport properties of SCFLWC mixes (90days)

\begin{tabular}{|cc|c|c|c|c|c|}
\hline Mix No. & $\begin{array}{c}\text { Compressive } \\
\text { Strength } \\
(\mathrm{MPa})\end{array}$ & $\begin{array}{c}\text { Tensile } \\
\text { Strength } \\
(\mathrm{MPa})\end{array}$ & $\begin{array}{c}\text { Flexural } \\
\text { Strength } \\
(\mathrm{MPa})\end{array}$ & $\begin{array}{c}\text { Modulus of } \\
\text { Elasticity } \\
(\mathrm{GPa})\end{array}$ & $\begin{array}{c}\text { Charge } \\
\text { passed } \\
(\text { Coulombs })\end{array}$ \\
\hline 1 & $(0 \% \mathrm{pp}, 0 \% \mathrm{FA})$ & 44.47 & 3.39 & 4.12 & 24.93 & 1760 \\
\hline 2 & $(0 \% \mathrm{pp}, 10 \% \mathrm{FA})$ & 42.67 & 3.21 & 3.95 & 23.21 & 323.7 \\
\hline 3 & $(0 \% \mathrm{pp}, 20 \% \mathrm{FA})$ & 40.26 & 3.10 & 3.65 & 21.29 & 552.5 \\
\hline 4 & $(0 \% \mathrm{pp}, 30 \% \mathrm{FA})$ & 33.89 & 2.28 & 3.08 & 20.11 & 409.05 \\
\hline 5 & $(0.2 \% \mathrm{pp}, 0 \% \mathrm{FA})$ & 42.67 & 3.42 & 4.38 & 25.68 & 1368 \\
\hline 6 & $(0.4 \% \mathrm{pp}, 0 \% \mathrm{FA})$ & 40.62 & 3.47 & 4.44 & 24.82 & 1058.6 \\
\hline 7 & $(0.6 \% \mathrm{pp}, 0 \% \mathrm{FA})$ & 33.05 & 3.35 & 4.33 & 24.61 & 1226.4 \\
\hline $8(0.2 \% \mathrm{pp}, 10 \% \mathrm{FA})$ & 40.02 & 3.51 & 4.66 & 23.54 & 694.2 \\
\hline $9(0.4 \% \mathrm{pp}, 10 \% \mathrm{FA})$ & 39.42 & 3.66 & 4.68 & 22.79 & 647.4 \\
\hline $10(0.6 \% \mathrm{pp}, 10 \% \mathrm{FA})$ & 33.41 & 3.40 & 4.30 & 22.47 & 753.3 \\
\hline $11(0.2 \% \mathrm{pp}, 20 \% \mathrm{FA})$ & 40.02 & 3.45 & 4.30 & 21.07 & 518.5 \\
\hline $12(0.4 \% \mathrm{pp}, 20 \% \mathrm{FA})$ & 38.82 & 3.52 & 4.40 & 20.65 & 339.7 \\
\hline $13(0.6 \% \mathrm{pp}, 20 \% \mathrm{FA})$ & 32.69 & 3.39 & 4.13 & 17.65 & 574 \\
\hline $14(0.2 \% \mathrm{pp}, 30 \% \mathrm{FA})$ & 39.66 & 3.36 & 3.33 & 20.33 & 392 \\
\hline $15(0.4 \% \mathrm{pp}, 30 \% \mathrm{FA})$ & 38.58 & 3.43 & 3.53 & 20.11 & 344.4 \\
\hline $16(0.6 \% \mathrm{pp}, 30 \% \mathrm{FA})$ & 32.21 & 3.13 & 3.47 & 19.90 & 491.4 \\
\hline
\end{tabular}




\section{Compressive strength}

The compressive strength tests results of SCFLWC mixes are represented in figure 1. With the increase in fly ash content from 0-30\% and zero percent fiber content, SCC mixes developed compressive strengths between 37 and $28.2 \mathrm{MPa}$ at 28 days. As shown here a reduction in compressive strength equal to $24 \%$ by increasing fly ash content up to $30 \%$, where the water/binder was kept constant for all mixes. Also, Table 6 and figure 1 illustrate the main mix results containing polypropylene fibers. The test results show that polypropylene fibers have slightly negative impact on compressive strength of the material. For example at $10 \%$ FA the compressive strength were $33.7,32$ and $27.2 \mathrm{MPa}$ for $0.2,0.4,0.6$ percent PP fibers, respectively. The slightly reduction of compressive strength was increased by increasing fiber content from $0.2 \%$ to $0.6 \%$ at all levels of fly ash. Mainly, LWA aggregates do not enhance the strength of concrete when a high compressive force is applied. If it will not enhance the strength of LWA aggregate; it will detach the cement joint and break it. Thus, the LWA aggregates have low compressive strength and they cannot tolerate considerable forces. Finally from the compressive test results obtained in this research, it may be concluded that PP fibers have no obvious effect on compressive strength of concrete.

The development of the concrete compressive strength vs. time is shown in Table $6 \& 7$ and figure 1 for all concrete types. Although the all mix proportions were identical even in terms of water/binder $(\mathrm{w} / \mathrm{b})$ ratios, the former developed considerably higher compressive strength (by about 18-20\%) at identical concrete age 90days. There are a number of factors which may have contributed to this behavior. It might due to this fact that, at the early age, FA, had a low pozzolanic reaction activity, at the later age, the calcium hydroxide $(\mathrm{CH})$ resulting from the primary cement hydration reacted with FA, to produce a secondary hydration.

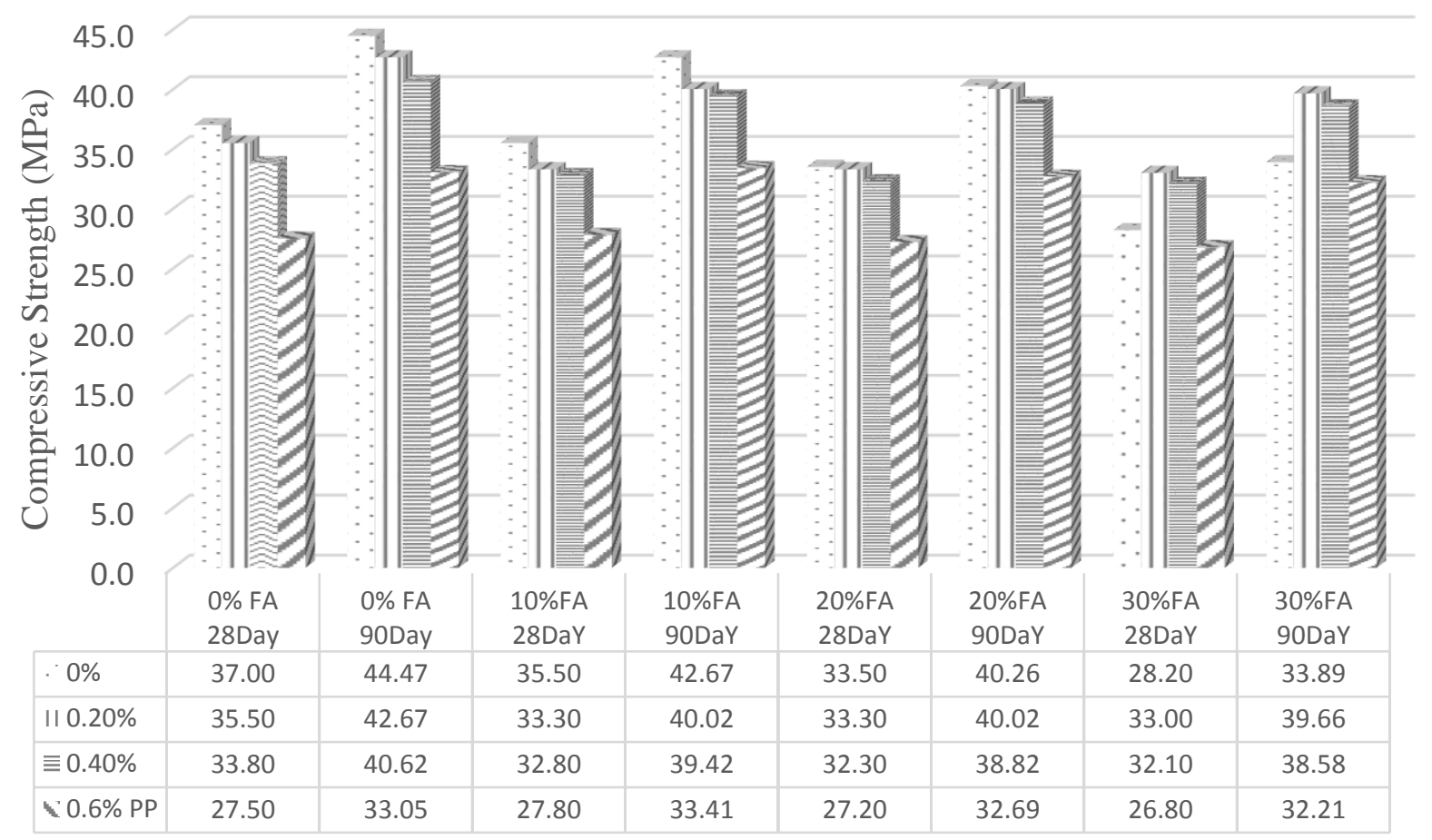

Figure 1. Variation of compressive strength in relation to levels of PP fibers and FA for 28 \& 90 day. 


\section{Tensile strength}

Splitting tensile strength test results of SCFLWC mixes are given in Table $6 \& 7$, and represented in figure 2. SCC mixes achieved splitting tensile strength from 2.9 to $1.95 \mathrm{MPa}$ at 28days, with the increase in fly ash content from 0 to $30 \%$ at zero percent PP fibers. The increase in the replacement level of FA, resulted in a reduction in the tensile splitting strength of the SCC. Also test was conducted just to demonstrate the differences of the mixes containing polypropylene fibers with those without it (where the percentage is zero). The test results are shown in Table 6 . When $0.2 \%$ and $0.4 \%$ samples containing polypropylene were tested the maximum force cracked the cylinder, it split down, i.e. polypropylene fibers prevented the cylinder from rupturing. When polypropylene fibers are added to the SCFLWC concrete mix, they become viscid, thus LWA aggregates in SCC mix are modified when they are added to the mix. Test results for split cylinder are compared in figure 2. The maximum rate of increasing of tensile strength in the mix of $0.4 \%$ polypropylene containing at $10 \% \mathrm{FA}$, SCFLWCC is $14 \%$. The results demonstrate that added polypropylene fibers can increase tensile strength of SCFLWC concrete by as much as $14 \%$, when the rate is enhanced based on the volume percentage of the fabrics.

The tendency of the tensile splitting strength of the SCC to reduce with the increase in the replacement level of FA, 28 days was reported. At 90 days, the difference of the tensile splitting strength of the control SCC, FA, samples was insignificant. A considerably higher tensile splitting strength (by about 16-17\%) at identical concrete age 90days compared with 28 days tensile splitting strength. Also, the contribution of pp. to the splitting strength of the SCC was the higher than that of FA, as shown in Table $6 \& 7$ and figure 2 .

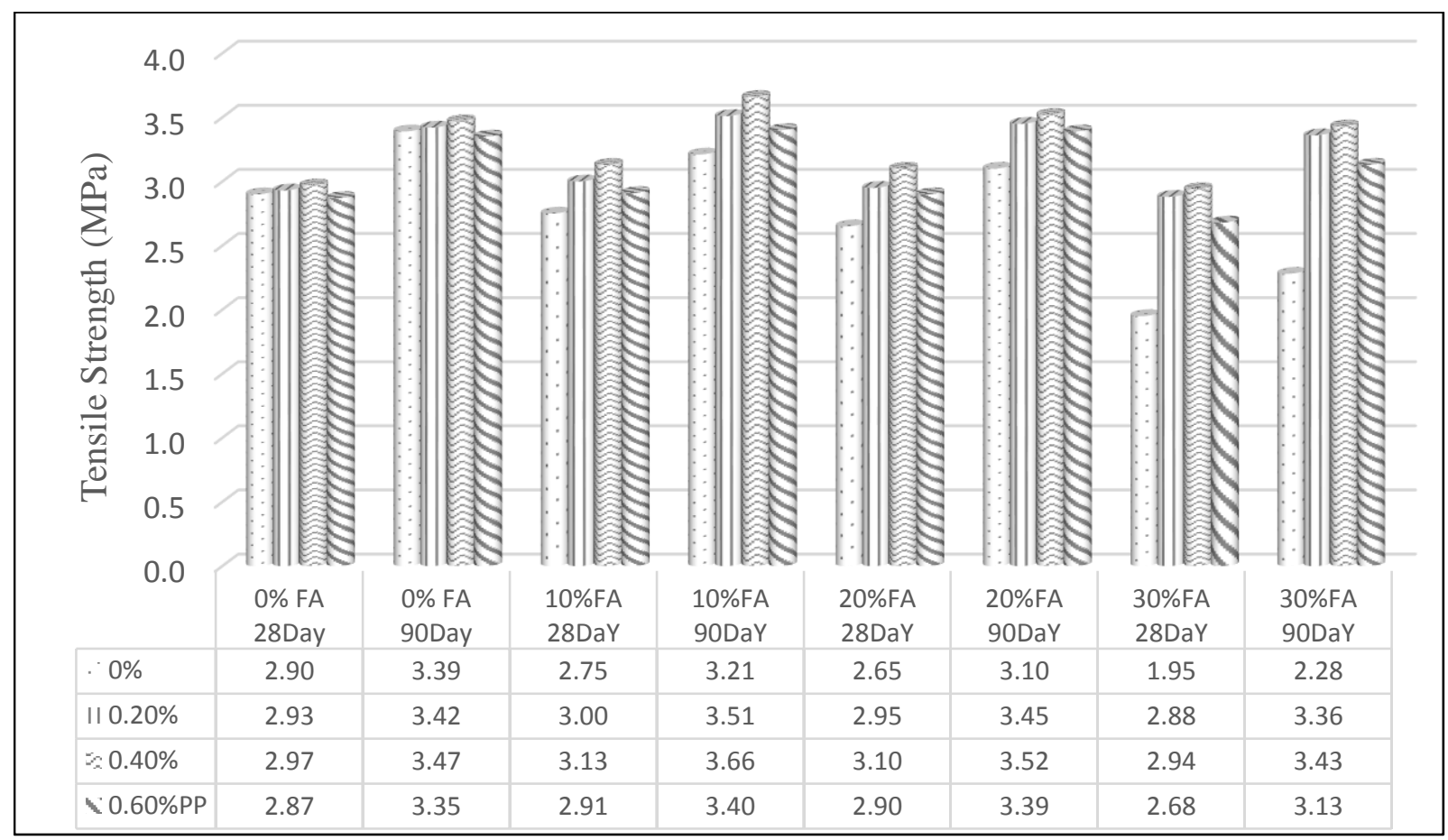

Figure 2. Variation of tensile strength at different levels of PP fibers and FA.

\section{Flexural strength}

According to the study, all of the samples ruptured at two points. The test results of the maximum force on the sample were recorded and then calculated the modulus of rupture. Similar to the splitting tensile strength test results of SCC mixes the flexural strength increased with a decrease in the percentage of the fly ash. 
SCC mixes achieved flexural strength from 3.1 to $2.32 \mathrm{MPa}$ at 28 days, with the increase in fly ash content from 0 to $30 \%$. PP fibers have a considerable effect on flexural strength. PP fibers increased the flexural strength up to 3.54 with $10 \%$ FA and $0.4 \%$ PP fiber. Also the rupture module that was reported in Table 6 and shown in figure 3 shows an ascending trend when the volume percentage of polypropylene fibers is increased and for the maximum increase of the fibers by $0.4 \%$ rupture modules is increased by about $22 \%$. The inclusion of fiber in LWAC increases its flexural strength. The reason is that, after matrix cracking, the fibers will carry the load that the concrete sustained until cracking by the interfacial bond between the fibers and the matrix. Therefore, the fibers resist the propagation of cracks and do not fail suddenly, which causes an increase in the load carrying capacity.

The flexural strength of various specimens at 90 days are shown in figure 3. The results reveal that all mixes has highest flexural strength at 90 days compared with flexural strength at 90 days by about $30-33 \%$. The contribution of PP fibers for enhancing flexural strength is more pronounced.

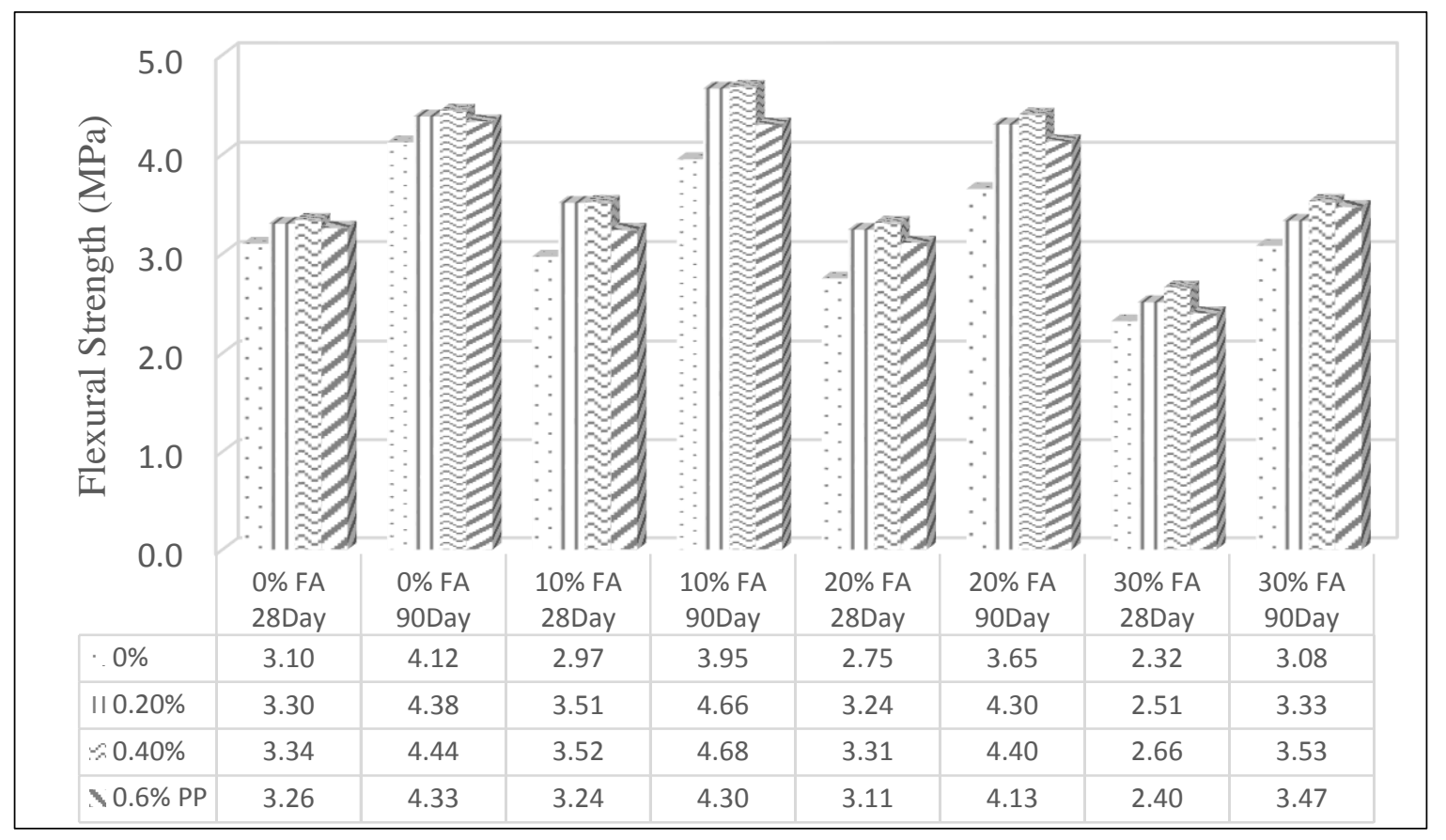

Figure 3. Variation of flexural strength in relation to levels of PP fibers and fly ash.

\section{Elastic modulus:}

The test is to specify elastic module of SCFLWC. Samples of the cylinder splitting tensile strength were tested on 28th day. Compressive tension is increased by $30 \%$ for the mix cylinder samples to obtain tension strength and the value of displacement change. It is possible to obtain elastic module of the concrete when a compressive force is applied. According to the obtained results, polypropylene fibers do not impact on these concretes and the changes are slight. As shown in Table 6 and figure 3, when the fibers are increased in the mixes, the increased rates or decrease rates are negligible. However, depending on the dosage of polypropylene fiber and fly ash contents, it may decrease modulus of elasticity up to $20 \%$ [Kayali et al 2003; Mazaheripour 2011]. For PP fibers, the maximum increase in modulus of elasticity was reported up to about $3 \%$. Currently, polypropylene fiber as one of the components of concrete with a low modulus of elasticity plays its role by bridging mechanism. In respect of the reason for reduction in the modulus of elasticity of polypropylene fiber Scoria LWAC, Previous work [Mazaheripour 2011] explained that this is probably due to the reduced compaction of the concrete. They demonstrated that such a reduction in compaction is due to the size and shape of the aggregate, which are not appropriate in respect of the size of 
the fiber used. It was also noticed that the fly ash content is more pronounced negative effect on modulus of elasticity.

In addition, the effect of the replacement level of FA on the static modulus of elasticity was not very sensitive as the compressive strength. At the same cuing period and the replacement level, a higher static modulus of elasticity for all mixes by about $07 \%$ at 90 days compared with 28 days modulus of elasticity as reported in Table $6 \& 7$ and represented in figure 3.

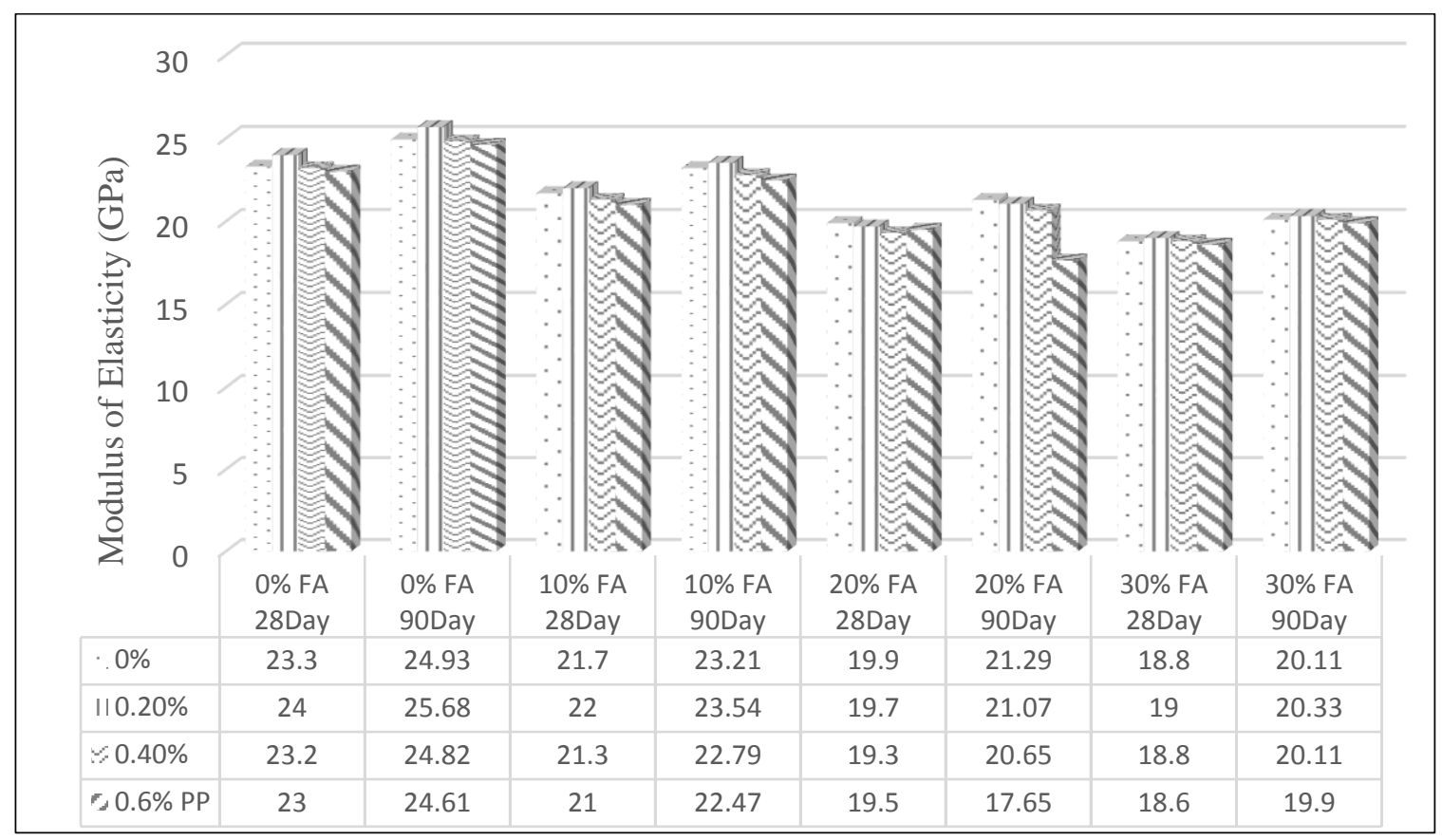

Figure 4. Variation of modulus of elasticity in relation to levels of PP fibers and fly ash.

\section{Transport properties: "Chloride penetration resistance"}

\subsection{Impact of fly ash}

The ability of concrete to resist the penetration of chloride ions is a critical parameter in determining the service life of reinforced concrete structures exposed to deicing salts or marine environments. The measurement concerns the chloride ions that come into concrete and also those flowing through the samples. Rapid chloride permeability test results of SCC mixes (with and without fibers) are given in Table 7 and represented in figure 5 .

It is evident from these results that all SCC mixes made with fly ash reduced the rapid chloride ion penetrability to the very low range (less than 1000 Coulomb) at the age 28 days. The incorporation of fly ash resulted in a reduction in Coulomb charges. The Coulomb charge of SCCLWC (30\% fly ash) was 505 Coulomb, indicating high chloride penetration resistance. In the study, the charge in the mixes varied with the increase in fly ash content. According to ASTM 1202-97 it can be said that it exhibited a very low stat, increasing in fly ash content above $10 \%$, leads to decrease in chloride penetration was observed. It was reported that the use of fly ash decreased the rapid chloride penetration Coulomb value of concrete and the presence of fly ash [Patel et al 2004] could improve the permeability of concrete due to its capability of transforming large pores of concrete into small pores and reducing micro cracking in the transition zone. The reduction of chloride migration due to presence of fly ash can be explained partially by the fact that spherical particles of fly ash could improve the particle density in the matrix and the interface zone between aggregates and paste. Also, [Nehdi et al 2004] have reported that the presence of fly ash reduced the 
penetrability from approximately 3000 Coulomb to less than 1000 Coulomb. At zero percent of FA, the value of the charges passed was greater than 2000 Coulomb implying dense SCC mix structure. According to ASTM 1202-97 it can be classified as a moderate stat. while the impact of fiber content change the stat of chloride ion penetration resistance from moderate to low category stat, but by adding the fly ash to the concrete mix the state change to very low state. It was reported that the fly ash contents is more pronounced positive effect on chloride ion penetration resistance compared with fiber contents.

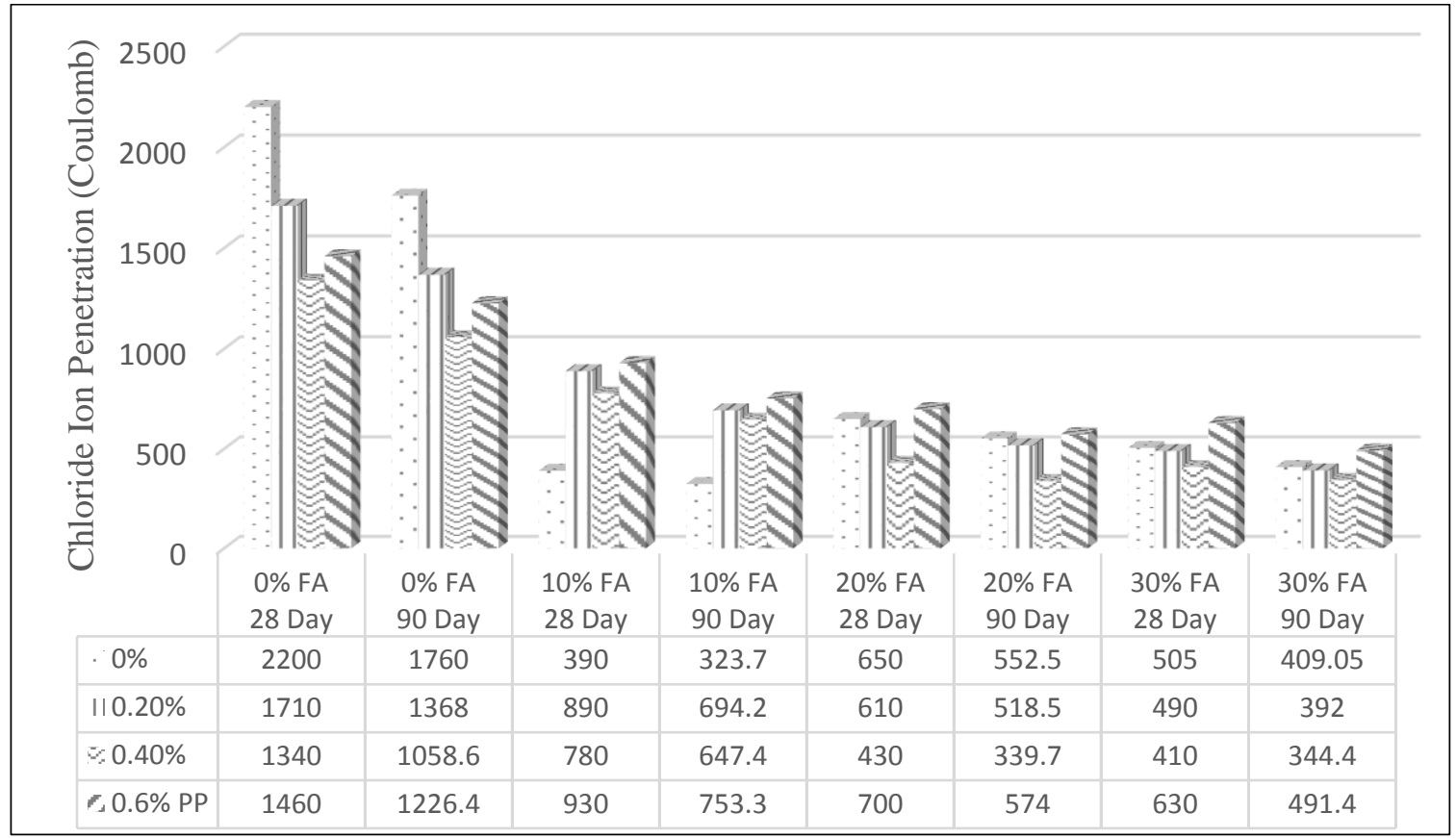

Figure 5. Chloride ion permeability of SCFLWC at different levels of PP fibers and FA

The chloride permeability values of concretes at 90 days were less than of the permeability values at 28 days by about $27-31 \%$. These results change the state of chloride ion penetration resistance from low to very low category state. as explained in Table $6 \& 7$ and represented in figure 5 . This may be due to that lightweight aggregate concrete had the least chloride concentration and even lower than similar strength normal weight concrete. The explanation to this phenomenon was likely to be the reservoir action of the lightweight aggregates possessing high absorption capacity that ranges from around $8 \%$ to sometimes more than $20 \%$. These aggregates would act as protective reservoirs to the rest of the matrix and would absorb the chloride laden solution [Kayali 2005].

\section{CONCLUSION}

Based on the results presented in this paper, the following conclusions will be drawn:

- The (SCFLWC) mixes suitable for structural applications were developed using locally available natural lightweight coarse and fine aggregates. The mixes developed had a compressive strength range of $27-42 \mathrm{MPa}$; an air dry density of $1700-200 \mathrm{~kg} / \mathrm{m}^{3}$; and a high degree of workability.

- The SCFLWC mixes developed. Splitting tensile strength developed was from 2.68, to $2.9 \mathrm{MPa}$. Flexural strength developed was from 2.4 to 3.1 MPa. The highest tensile and flexural strength was recorded in the mix with $0.4 \%$ pp fiber. The compressive strength increased with a decrease in the percentage of the fly ash. In this way the maximum improvement in tensile strength is $14 \%$ while the 
maximum improvement in flexural strength is $22 \%$. An improvement of all mechanical properties was reported at 90 days compared with at 28 days results.

- Polypropylene fibers have no detectable effect on mechanical properties of hardened concrete at volume percent $0.2 \%$ volume ratios. Besides, addition of $0.4 \%$ PP fibers in concrete mixes has a negligible influence on compressive characteristics. However, $0.4 \%$ PP fibers increased both flexural strength and tensile strength to some extent. The improving effect of PP fibers is more recognizable in the mixes which do not contain fly ash. So, the minimum amount of polypropylene fibers to be used in SCFLWC to enhance flexural and tensile strength is about $0.4 \%$ by volume of concrete.

- Generally polypropylene fibers do not have an impact on the compressive strength and elastic module of SCFLWC. The changes in both qualities are irregular and insignificant as the volume percentage of polypropylene fibers is increased at 28 days.

- SCLWC mixes made with fly ash reduced the rapid chloride ion penetrability to the very low range (less than 1000 Coulomb) at 90 days. It can be concluded that the impact of fly ash on chloride penetration resistance is more pronounced that the impact of pp fibers

\section{ACKNOWLEDGEMENT}

The authors would like to acknowledge the financial support of this research provided by the Institute of Scientific Researches at Umm Al-Qura University, Makkah, Saudi Arabia.

\section{REFERENCES}

Abukhashaba, M. I., Mostafa, M. A. \& Adam, I. A. (2014). Behavior of self-compacting fiber reinforced concrete containing cement kiln dust. Alexandria Engineering Journal, 53, 341-354.

Akcay, B. \& Tasdemir, M. A. (2012). Mechanical behavior and fiber dispersion of hybrid steel fiber reinforced self-compacting concrete. Construction and Building Materials, 28, 287-293.

Alengaram, U. J., Al Muhit, B. A., \& Bin Jumaat, M. Z. (2013). Utilization of oil palm kernel shell as lightweight aggregate in concrete - A review. Construction and Building Materials, 38, 161-172.

ASTM C39/C39M-99 Standard test method for compressive strength of cylindrical concrete specimens. Annual Book of ASTM Standards, 7 pages.

ASTM C469-94 Standard test method for static modulus of elasticity and Poisson's ratio of concrete in compression. Annual Book of ASTM Standards, 5 pages.

ASTM C496-96 Standard test method for splitting tensile strength of cylindrical concrete specimens. Annual Book of ASTM Standards, 5 pages.

ASTM C78-94 Standard test method for flexural strength of concrete (using simple beam with third-point loading). Annual Book of ASTM Standards, 4 pages.

Beyciog, A. \& Aruntas, H. Y. (2014). Workability and mechanical properties of self-compacting concretes containing LLFA, GBFS and MC. Construction and Building Materials, 73, 626-635.

Bogas, A., Gomes, A. \& Pereira, M. F. C. (2012). Self-compacting lightweight concrete produced with expanded clay aggregate. Construction and Building Materials, 35, 1013-1022.

Corinaldesi, V. \& Moriconi, G. (2004). Durable fiber reinforced self-compacting concrete. Cement and Concrete Research, 34, 249-254.

Cui, H. Z., Yiu Lo, T., Memonb, Sh. A. \& Xu, W. (2012). Effect of lightweight aggregates on the mechanical properties and brittleness of lightweight aggregate concrete. Construction and Building Materials, 35, 149-158. 
D’Aloia, L., Schwartzentruber, R., Roy, L. \& Cordin, J. (2006). Rheological behavior of fresh cement pastes formulated from a self-compacting concrete (SCC). Cement \& Concrete Research, 36, 12031213.

EFNARC. (2002). European federation of national trade associations representing producers and applicators of specialist building products. Specification and guidelines for self-compacting concrete. February, Hampshire (UK).

El-Dieb, A. S. \& Reda-Taha, M. M. (2012). Flow characteristics and acceptance criteria of fiber-reinforced self-compacted concrete (FR-SCC). Construction and Building Materials, 27, 585-596.

Ferrara, L., Bamonte, P., Caverzan, A., Musa, A. \& Sanal, I. (2012). A comprehensive methodology to test the performance of Steel Fiber Reinforced Self-Compacting Concrete (SFR-SCC). Construction and Building Materials, 37, 406-424.

Hassanpour, M., Shafigh, P. \& Bin Mahmud, H. (2012). Lightweight aggregate concrete fiber reinforcement - A review. Construction and Building Materials, 37, 452-461.

Japanese Society of Civil Engineering. (1998). Guide to construction of high flowing concrete. Tokyo: Gihoudou Pub.

K.H. Khayat, G. De Schutter (Eds.). (2014). Mechanical Properties of Self-Compacting Concrete. State-ofthe-Art Report of the RILEM Technical Committee 228-MPS, vol. 14, on Mechanical Properties of SelfCompacting Concrete.

Kayali O, Zhu B. (2005) Chloride induced reinforcement corrosion in lightweight aggregate high-strength fly ash concrete. Construction and Building Material; 19(4): 327-36.

Kayali, O., Haque, M. N., \& Zhu, B. (2003). Some characteristics of high strength fiber reinforced lightweight aggregate concrete". Cement \& Concrete Composites, 25(2), 207-213.

Libre, N.A., Shekarchi, M., Mahoutian, M., \& Soroushian, P. (2011). Mechanical properties of hybrid fiber reinforced lightweight aggregate concrete made with natural pumice. Construction and Building Materials, 25(5), 2458-2464.

Mazaheripour, H., Ghanbarpour, S., Mirmoradi, S. H. \& Hosseinpour, I. (2011). The effect of polypropylene fibers on the properties of fresh and hardened lightweight self-compacting concrete. Construction and Building Materials, 25, 351-358

Nehdi, M., Pradhan, M., \& Koshowski, S. (2004). Durability of self-consolidating concrete incorporating high-volume replacement composite cements. Cement \& Concrete Research, 11, 2103-2112.

Patel, R., Hossain, K. M.A., Shehata, M., Bouzoubaa, N. \& Lachemi, M. (2004). Development of Statistical models for mixture design of high-volume fly ash self-consolidation concrete. ACI Mater. J., 101(4), 294-302.

R. Madandoust, M. M. Ranjbar, Reza Ghavidel, S. Fatemeh Shahabi. (2015). Assessment of factors influencing mechanical properties of steel fiber reinforced self-compacting concrete Materials \& Design, 83, 284-294.

Salehian, H. \& Barros, J. A. O. (2015). Assessment of the performance of steel fiber reinforced selfcompacting concrete in elevated slabs. Cement \& Concrete Composites, 55, 268-280.

Shannag, M. J. (2011). Characteristics of lightweight concrete containing mineral admixtures. Construction and Building Materials, 25, 658-662.

Torrijos, M.C., Barraga, B.E. \& Zerbino, R.L. (2008). Physical-mechanical properties, and macrostructure of plain and fiber reinforced self-compacting concrete. Construction and Building Materials, 22, 17801788. 
Wang, C. Y., Jic, K. Y., Cheol, S. H. \& Young. M. H. (2003). An experimental research on the fluidity and mechanical properties of high strength lightweight self-compacting concrete. Cement \& Concrete Research, 36, 1595-602.

Wu, Z., Zhang, Y., Zheng, J. \& Ding, Y. (2009). An experimental study on the workability of selfcompacting lightweight concrete. Construction and Building Materials, 23, 2087-2092. 